Thesis summary

\title{
THE RELATIONSHIPS OF GROWTH AND FLOWERING TO NONSTRUCTURAL CARBOHYDRATE RESERVES IN. CHIONOCHLOA SPP.
}

\author{
(Ph.D. thesis, University of Otago)
}

\section{J. PAYTON}

The relationships of growth and flowering to nonstructural carbohydrate reserve storage and the influence of the pastoral management practice of burning on these relationships were investigated in Chionochloa rigida and $\mathrm{C}$. macra on the Old Man Range, Central Otago.

Rates of growth, as measured by the elongation of the youngest exposed leaf, decreased significantly with increasing altitude. They were significantly greater in C. rigida than in C. macra. Spring burning increased rates of leaf elongation, relative to those of unburnt plants during the first two seasons following fire, C. rigida > C. macra. From the second post-fire season onwards, growth rates in C. rigida were depressed relative to those of unburnt plants. This was more marked in the latter half of the season. Growth rates were on a par with those of unburnt plants by about the fourteenth season after fire. Reburning after three seasons produced a significantly smaller response to fire, not evident when plants were reburned after 5 to 12 years. Fire stimulated production of new leaves and new tillers over the subsequent two seasons. Thereafter values were on a par with those of unburnt plants. Reburning 3, 5 or 12 years later produced non-significant reductions in this response. Tussock biomass was markedly reduced by fire, with $\mathrm{C}$. rigida plants at $1220 \mathrm{~m}$ requiring in excess of fifteen seasons before mean biomass values again equalled those of corresponding unburnt plants. Flowering was stimulated by fire only in the first post-fire season. Thereafter it was considerably depressed in burnt plants. Values were approaching those for unburnt plants by the fourteenth postfire season. Documentation of the substantial delay in a snow tussock's recovery from the phyiological effects of burning is an important aspect of the results.

Sucrose is the major component of the nonstructural carbohydrate reserves in both species, together with smaller amounts of starch, glucose and fructose. Reserve carbohydrate storage 
occurs in both leaf and stem tissue. Roots were consistently low in nonstructural carbohydrates. Carbohydrate reserves were lowest during the period of active growth, increasing towards the end of the growing season. Reserve carbohydrate storage increased with altitude with C. macra $>$ C. rigida.

Carbon-14 labelling provided evidence for the use in new growth of assimilates stored from the previous season, albeit on a small scale. Increased growth rates following fire led to lower levels of reserve carbohydrate storage in the two seasons following fire. Thereafter, corresponding to the lowered growth rates, mean levels of reserve carbohydrate storage were non-significantly higher than in corresponding unburnt plants. 